\title{
Bronchial carcinoma in patients with pre-existing unilateral lung disease
}

\author{
TAKESHI YONEYAMA, TSUGUO NARUKE, \\ K E I I CH I SEMASU, and SHICHIRO ISHIKA W A \\ Department of Surgery, the National Cancer Centre, Tokyo, Japan
}

\begin{abstract}
Yoneyama, T., Naruke, T., Suemasu, K., and Ishikawa, S. (1976). Thorax, 31, 650-651. Bronchial carcinoma in patients with pre-existing unilateral hung disease. Forty-six cases of primary bronchogenic carcinoma occurring in patients with other unilateral pleuropulmonary diseases were studied. In 37 cases $(80.4 \%)$ carcinoma developed in the previously healthy lung. All but one squamous-cell carcinoma and all of five undifferentiated small-cell carcinomas developed in the previously healthy lung while 7 of 15 adenocarcinomas were in the lung with impaired ventilation. It is suggested that the bronchial epithelium of the healthy lung is more exposed to exogenous carcinogens than that of the diseased, underventilated lung, resulting in a higher risk of development of squamous-cell and undifferentiated small-cell carcinoma.
\end{abstract}

It is well known that exogenous carcinogens such as cigarettes are important factors in the aetiology of bronchogenic carcinoma.

If the ventilation of one lung is reduced by unilateral pleural or pulmonary disease, it might be assumed that inhaled carcinogens would be more likely to affect the healthy, relatively hyperventilated lung. The present study was undertaken to investigate whether this is so.

\section{MATERIAL AND METHODS}

Between May 1962 and December 1973, 1425 patients with primary bronchogenic carcinoma were admitted to the National Cancer Centre Hospital. From these we have found 46 in whom one lung had been severely damaged by previous pleuropulmonary disease. The clinical records of these patients have been examined for information about age, sex, smoking habit, past history, and cell type.

\section{RESULTS}

Clinical summaries of the 46 cases are available on application to the authors.

The normal lung was the site of the tumour in 37 cases $(80 \cdot 4 \%)$.

Age at the time of diagnosis of the tumour ranged from 34 to 86 years, but, in the majority, it was over 60 years. Forty-one patients out of 46 were male.

Thirty-six of 39 men and 3 of 4 women were $\stackrel{\mathbb{D}}{\mathbb{Q}}$ current smokers. Many of these were heavy smokers (more than 20 cigarettes per day). In- 윽 formation on smoking was not available for the other three patients.

Pulmonary tuberculosis and pleurisy were the most frequent causes of the unilateral lung disease (see Table I).

T A B L E I

PAST PLEUROPULMONARY DISEASE

\begin{tabular}{l|c}
\multicolumn{1}{c|}{ Diagnosis } & No. of Cases \\
\hline Pulmonary tuberculosis & 25 \\
(Thoracoplasty) & $(8)$ \\
Pleurisy & 13 \\
Bronchiectasis & 3 \\
Pyothorax & 1 \\
Atrophy of hemithorax & 1 \\
Pneumonia & 1 \\
Chest trauma & 1 \\
Unknown & 1 \\
\hline Total & 46 \\
\hline
\end{tabular}

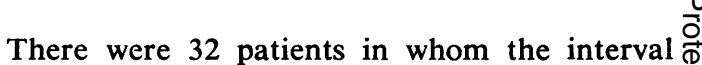
between previous chest disease and development $\frac{?}{\mathbb{Q}}$ of the tumour was known; there were 14 in whom 
the interval was over 20 years, five with an interval of $10-20$ years, and in 13 the interval was less than 10 years.

Thirty-two cases were diagnosed pathologically and 11 cases were proved cytologically. There were 20 squamous-cell carcinomas (42\%), 16 adenocarcinomas $(36 \%)$, and five undifferentiated small-cell carcinomas (11\%) (Table II). These figures are similar to those found among patients submitted to surgery in our hospital.

T A B L E I I

CELL TYPE DISTRIBUTION AND LOCALIZATION OF TUMOUR

\begin{tabular}{l|c|c|c}
\hline \multicolumn{1}{c|}{ Cell Type } & No. of & Tumour detected in \\
\cline { 3 - 4 } & $\begin{array}{c}\text { Healthy } \\
\text { Cases }\end{array}$ & $\begin{array}{c}\text { Lung } \\
\text { Diseased } \\
\text { Lung }\end{array}$ \\
\hline Squamous-cell & 20 & 19 & 1 \\
Adenocarcinoma & 16 & 9 & 7 \\
Sarge-cell undifferentiated & 5 & 4 & 1 \\
\hline Total & 5 & 5 & 0 \\
\hline
\end{tabular}

All but one squamous-cell carcinoma and all five undifferentiated small-cell carcinomas developed in the normal lung whereas the adenocarcinomas were evenly distributed between the two lungs.

\section{DISCUSSION}

Numerous cases of lung cancer associated with pulmonary tuberculosis have been published, and possible relationships between these two diseases have been discussed for many years (Drymalski and Sweany, 1948; Weissman, 1956). On studying the literature, we have been impressed by the fact that, in many cases, the tumour was detected in the healthy lung.

This has also been noted in the analysis of lung caricer cases with a second primary tumour collected from reports of long-term survivors after surgery (Watson, 1965; Smith, 1970; Shields and Robinette, 1973).

Squamous-cell carcinoma and undifferentiated small-cell carcinoma have been classified by Kreyberg (1962) as group 1 cancers which have been related to exogenous carcinogens.

On the other hand, Kreyberg group 2 adenocarcinoma was not associated with exogenous factors.

These observations may explain why, in the present series, all but one of the 25 Kreyberg group 1 tumours occurred in the better ventilated lung while the Kreyberg group 2 tumours were evenly distributed between the two lungs.

\section{REFERENCES}

Drymalski, G. W. and Sweany, H. C. (1948). The significance of pulmonary tuberculosis when associated with bronchogenic carcinoma. American Review of Tuberculosis, 58, 203.

Kreyberg, L. (1962). Histological lung cancer types: a morphological and biological correlation. Acta Pathologica et Microbiologica Scandinavica, Supplement, 157, 1.

Shields, T. W. and Robinette, C. D. (1973). Longterm survivors after resection of bronchial carcinoma. Surgery, Gynecology and Obstetrics, 136, 759.

Smith, R. A. (1970). Long-term clinical follow-up after operation for lung carcinoma. Thorax, 25, 62.

Watson, W. L. (1965). Ten-year survival in lung cancer. A study of 56 cases. Cancer, 18, 133.

Weissman, H. (1956). Bronchogenic carcinoma and pulmonary tuberculosis: problems in diagnosis with special reference to antituberculous chemotherapy. American Review of Tuberculosis and Pulmonary Diseases, 73, 853.

Requests for reprints to: Dr. T. Yoneyama, Department of Surgery, National Cancer Centre, Tokyo, Japan. 